\title{
The Building Wealth and Health Network: methods and baseline characteristics from a randomized controlled trial for families with young children participating in temporary assistance for needy families (TANF)
}

Jing Sun ${ }^{3}$, Falguni Patel ${ }^{1}$, Rachel Kirzner ${ }^{4}$, Nijah Newton-Famous ${ }^{1}$, Constance Owens ${ }^{1}$, Seth L. Welles ${ }^{2}$ and Mariana Chilton ${ }^{1 *}$ (D)

\begin{abstract}
Background: Families with children under age six participating in the Temporary Assistance for Needy Families Program (TANF) must participate in work-related activities for $20 \mathrm{~h}$ per week. However, due to financial hardship, poor health, and exposure to violence and adversity, families may experience great difficulty in reaching selfsufficiency. The purpose of this report is to describe study design and baseline findings of a trauma-informed financial empowerment and peer support intervention meant to mitigate these hardships.

Methods: We conducted a randomized controlled trial of a 28-week intervention called Building Wealth and Health Network to improve financial security and maternal and child health among caregivers participating in TANF. Participants, recruited from County Assistance offices in Philadelphia, PA, were randomized into two intervention groups (partial and full) and one control group. Participants completed questionnaires at baseline to assess career readiness, economic hardship, health and wellbeing, exposure to adversity and violence, and interaction with criminal justice systems.
\end{abstract}

Results: Baseline characteristics demonstrate that among 103 participants, there were no significant differences by group. Mean age of participants was 25 years, and youngest child was 30 months. The majority of participants were women (94.2\%), never married (83.5\%), unemployed (94.2\%), and without a bank account (66.0 \%). Many reported economic hardship (32.0\% very low household food secure, $65.0 \%$ housing insecure, and $31.1 \%$ severe energy insecure), and depression (57.3\%). Exposure to adversity was prevalent, where $38.8 \%$ reported four or more Adverse Childhood Experiences including abuse, neglect and household dysfunction. In terms of community violence, $64.7 \%$ saw a seriously wounded person after an incident of violence, and $27.2 \%$ had seen someone killed. Finally, $14.6 \%$ spent time in an adult correctional institution, and $48.5 \%$ of the fathers of the youngest child spent time in prison.

* Correspondence: mmc33@drexel.edu

'Department of Health Management and Policy, Drexel University Dornsife

School of Public Health, 3600 Market Street, 7th Floor, Philadelphia, PA

19104, USA

Full list of author information is available at the end of the article 


\begin{abstract}
(Continued from previous page)
Conclusions: Baseline findings demonstrate that caregivers participating in TANF have suffered significant childhood adversity, adult violence exposure, and poverty-related stressors that can limit workforce success. High prevalence of housing and food insecurity, exposure to adversity, violence and criminal justice systems demands comprehensive programming to support families. Trauma-informed approaches to career readiness such as the Building Wealth and Health Network offer opportunities for potential success in the workforce.
\end{abstract}

Trial registration: This study is retrospectively registered with ClinicalTrials.gov

The Identifier is: NCT02577705

The Registration date is October 13, 2015

Keywords: Food insecurity, Adverse childhood experiences, Violence, Trauma, Poverty, TANF, Assets, Depression, Randomized controlled trial

\section{Background}

Families with young children under age six participating in the Temporary Assistance for Needy Families Program (TANF) that are deemed "work mandatory" are required to participate in work-related activities for at least $20 \mathrm{~h}$ per week in order to receive TANF benefits. However, due to financial hardship, poor health, and exposure to violence and adversity, the success families achieve through TANF participation can be limited. In partnership with the state of Pennsylvania Department of Human Services, this randomized control trial pilot, The Building Wealth and Health Network (The Network $\mathrm{RCT}$ ), is an ongoing study that seeks to evaluate effectiveness of an innovative intervention to address family hardships associated with exposure to adversity and violence, social isolation, and low financial capability in order to help families get on the pathway to selfsufficiency. This program is also meant to test a workforce development model that includes attention to mental, emotional, and financial health that can become a new model for TANF education and training programming. The Network RCT is a 28-week educational program with a full intervention group, a partial intervention group, and a control group. The full intervention includes helping participants to open a savings account, into which participants are provided a 1:1 match of up to 20 dollars a month; financial empowerment education; and trauma-informed peer support. This counts toward $6 \mathrm{~h}$ of work participation per week. The partial intervention includes the 1:1 matched savings accounts and financial education, counting for three hours of work participation per week. Network RCT staff document these hours along with other work participation hours up to $20 \mathrm{~h}$ per week as reported by participants, in the state data management system, Commonwealth Workforce Development System (CWDS). The control group participates in TANF activities as prescribed by County Assistance Income Maintenance Workers. This primarily consists of being required to participate in $20 \mathrm{~h}$ per week of state-supervised TANF mandated work participation or supervised job search activities.

Below, we describe The Network RCT research methods and program design. We also describe baseline characteristics of the sample of 103 participants, all of whom have a young child under age six and who were deemed to be required to comply with the $20 \mathrm{~h}$ per week work participation requirement. We describe their career readiness, hardship (food insecurity, housing insecurity and energy insecurity), self-rated health and depression, and exposure to violence and adversity, including history of incarceration. Baseline measures demonstrate that TANF participants with young children who are originally deemed "work mandatory" report a complex picture of career readiness. Additionally, they report high rates of financial hardship in relation to food, housing, and utilities, high rates of depression and poor health, developmental risk among their children, significant exposure to community violence, high rates of adverse childhood experiences, and a significant history of incarceration. Research has shown that TANF programs that prioritize health and wellbeing have a positive influence on helping families to find and keep employment and demonstrate movement towards selfsufficiency [1-5]. Rarely, however, are characteristics related to deep hardship such as homelessness and hunger coupled with high rates of violence exposure and incarceration taken into account in TANF education and training programs, nor do federal guidelines call for improving such metrics beyond employment and exit from TANF. We frame these hardship experiences as indicators of exposure to trauma, and suggest that TANF programs be built to explicitly address these hardships and integrate trauma-informed peer support approaches into job training and skill building. A trauma-informed intervention such as the Building Wealth and Health Network can not only improve mental health and wellbeing and create a path to self-sufficiency, but also, we suggest that given the theory developed around helping individuals overcome trauma and related isolation, peer support 
is a key component to any type of programming meant to have a positive impact on the health and wellbeing of caregivers' young children [6-9].

In 2013, 45.3 million people lived in poverty in the United States, including over one in five children under the age of six, yet only $27 \%$ of eligible families received TANF. In Pennsylvania, the number of people living in poverty is slightly higher than the national average but still only $31 \%$ of those eligible, received TANF in 2013 [10]. While child poverty increases the risk of poor health and developmental delays [11], many public assistance programs, such as the Supplemental Nutrition Assistance Program (SNAP), the Special Supplemental Nutrition Program for Women, Infants, and Children (WIC), and housing subsidies, protect vulnerable children from the negative effects of poverty $[12,13]$. However, it is unclear if TANF has demonstrated significant improvements in maternal and child wellbeing, in moving families out of poverty, or in fully preparing low-income families for success in the workforce $[14,15]$.

One of the goals of TANF is to provide job skills and education programs to support adults and their children as they enter the workforce. However, many families experience barriers to employment, which may prevent them from successfully transitioning off of TANF. This may be due in part to poor health among those receiving TANF, as approximately one third of TANF recipients have reported a work-limiting health condition $[4,5,16]$; and almost $43 \%$ of TANF recipients reported multiple types of disability including memory impairment, emotional/mental limitations, movement limitations, and sensory impairment [2]. In addition to the poor health and disability reported by TANF participants, they also report alarmingly high rates of exposure to violence and adversity in their communities and in their family relationships [17-20]. For instance, among TANF eligible families, rates of intimate partner violence are as high as $74 \%$ compared to up to $31 \%$ in the general community [21], posing a major barrier to employment [22-25]. While exposure to violence in adulthood indicates severe hardship, such exposure to violence across the lifespan, reaching back into childhood, is also reported at significantly higher rates among low-income families. Adverse childhood experiences (ACEs) consisting of physical and emotional abuse and neglect, sexual abuse, and household dysfunction, such as having a household member in prison, or witnessing domestic violence are especially prevalent among those receiving TANF [26]. ACEs and violence exposure are closely linked to work-limiting conditions such as depression, cardiovascular disease, food insecurity and other health conditions [27-30]. Exposure to ACEs has been linked to higher rates of worker absenteeism and stress surrounding work and finances in adulthood, indicating an association between ACEs and later financial stability [31]. Other related barriers to work are having a criminal record, or having served time in prison [16], and among female heads of household TANF recipients, the prevalence of interactions with the criminal justice system is quite high compared to other low income populations [16, 32]. Finally, when a parent of a young child is in prison, it can have detrimental effects on the child's development, which in turn, demands more attention, time and care by adult caregivers, creating more barriers to work [33]. Female heads of households who have a criminal history are at greater risk for reaching the federal time limit of 60 months of TANF receipt, which can exacerbate the barriers of obtaining employment [34]. Furthermore, children whose parents have a criminal history are at a greater risk of becoming involved in the criminal justice system and are more likely to exhibit high-risk behaviors than children in the general population [32].

High levels of adversity among TANF recipients and those living in poverty is a significant concern because adversity impacts physical and mental health [29, 35], academic achievement [36], employment [37], the development of executive skills such as working memory and cognitive controls [38, 39], and parenting of the next generation [40]. Emphasis on job search and work participation for families without attention to poor health and adversity can be a set up for failure. A recent RCT in Florida found that women with chronic health conditions receiving TANF, while deemed mandatory to work had greater difficulty attaining employment than women with the same characteristics who received Public Health Nursing care related to their health condition [4]. In addition, other investigators have found that social support and comprehensive approaches to social work that build resilience may have success in limiting the negative impacts of exposure to violence and adversity [41, 42]. However, the majority of TANF programs across the country rarely integrate such approaches, and in many states, TANF participants that are unable to meet the mandated work requirements, potentially due to poor health and exposure to violence and adversity, may be more likely to be "sanctioned," meaning they would either have their cash benefits reduced or cut off completely for a duration of time.

Families that receive sanctions are more likely to have significant health barriers to work participation [43]. Additionally, those who have been sanctioned reported higher rates of intimate partner violence [44], and physical and behavioral health problems [45, 46]. Sanctions can then increase hardships families already face. For instance, compared to families who have not been sanctioned, families that experience sanction report higher rates of household food insecurity [47], utility shut-offs 
[48], child hospitalizations [47], difficulty paying for health care [49], homelessness [50], and disruptions in children's schooling [51]. This is especially problematic as those who are sanctioned are more likely to have young children, putting those children at increased risk during sensitive developmental phases [11].

To compound the mental and physical barriers to work and self-sufficiency, TANF-eligible families, like many low-income families, have low financial literacy, poor or no credit history, few or no assets, and are unbanked (having no checking or savings account) or under-banked (having a bank account, but still primarily relying on alternative financial services such as check cashing and money orders) [52-55]. In order to supplement meager income, families may resort to earning income and spending money through the informal economy where they are paying higher fees for check cashing, paying bills, and acquiring loans [56]. This lack of access to mainstream financial institutions and activities can be crippling, as savings and other tangible assets play a critical role in helping shield families from unexpected income shocks, allowing families to weather periods of economic uncertainty without falling further into poverty [57-59]. Savings create a financial foundation, increase economic security, and can, over time, be invested into education for children. Asset building activities show improvements in health, greater civic and community involvement, and lower rates in the intergenerational transfer of poverty [59]. Savings can also reduce the extreme stress that often accompanies maternal depression [60]. Finally, the positive impacts of savings have held true even during the recession [61, 62]. It is true, however, that people who are participating in TANF have a very difficult time opening and maintaining a bank account, or savings account at all. In order to develop a new habit of saving, and to begin to create a seed kernel on which to build assets, even small increments of savings have been identified with ability to envision a future, set goals, and build knowledge and skills, as well as to be associated with positive education outcomes for children [57, 58, 63-66].

Overall, the evidence on effectiveness of education and training programs across the country points to the urgent need to pivot the approaches for education and training by integrating programming that helps to provide social support, build resilience, address health barriers, and overcome exposure to trauma and adversity. Evidence of the need to address trauma among families has become so apparent that the US agency that administers TANF, the Agency for Children and Families, is calling for trauma-informed approaches that incorporate approaches that address two generations (caregiver and child), rather than focusing solely on either caregiver or child [67].

\section{Methods}

The Building Wealth and Health Network Randomized Controlled Trial (Network RCT)

The Building Wealth and Health Network Randomized Controlled Trial (Network RCT) is built to evaluate a pilot intervention that develops a new model of public benefits provision, meant to leverage participants' own strengths to become financially self-sufficient. The Network RCT provides asset-building activities and trauma-informed peer support to low-income caregivers of young children under the age of six who are participating in TANF. The goal of the program is to increase the caregiver's financial, human, and social capital in order to improve financial security and maternal and child health.

\section{Network RCT research design Population}

This study has been approved by the Drexel University Institutional Review Board. Study recruitment took place in June and July of 2014 at three County Assistant Offices (CAOs) in Philadelphia where TANF participants who are residents of South or Southwest Philadelphia come to enroll and/or recertify for benefits. Participants were included in the study if they were at least 18 years old, had been receiving TANF cash assistance for 4 years or less, had at least one child under six years old, and were considered "mandatory to work" for $20 \mathrm{~h}$ per week by the federal welfare guidelines. Mandatory means that participants have no documented physical or mental health barriers or documented caregiving responsibilities (for a newborn or a disabled child or adult) that will prevent them from working. Participants were excluded from the study if they had been involved with bank fraud in the past or had a household member already enrolled in the program.

Figure 1 presents the study recruitment procedure. During their visit, TANF participants were screened by CAO Intake Workers for their eligibility. At that time, recruitment staff reconfirmed participants' eligibility based on TANF participation history and child's age. No medical or social screening procedures were used. After they verified eligibility, the Intake workers, informed participants about the Building Wealth and Health Network. A total of 180 participants that were present at the CAO during recruitment days were referred to the Network RCT by CAO staff upon initial screening for eligibility. Upon re-screening by study team members, 8 people were determined to be ineligible. Upon explaining the program, 27 people declined to participate and wished to be referred back to the intake worker so that they could enroll in a traditional job-search program, or apply their existing education or employment hours towards the work participation requirement. One hundred 


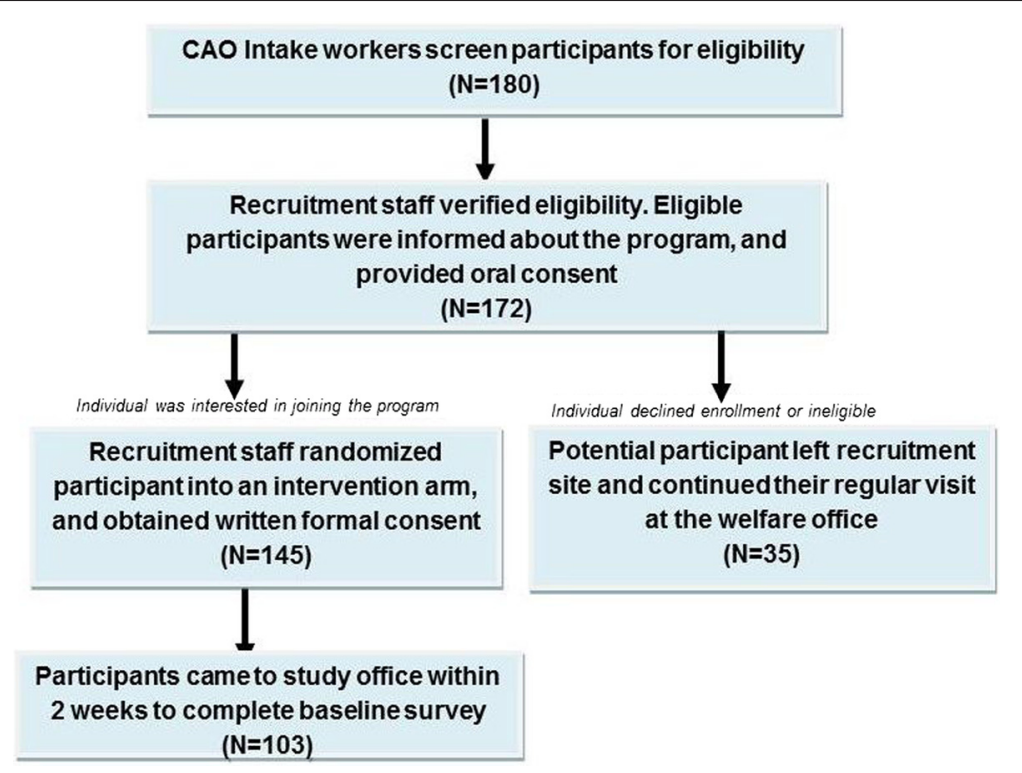

Fig. 1 Recruitment and Randomization Procedure

forty-five people agreed to participate in the study. All were randomized into the three intervention groups and provided informed consent. After randomization, participants were scheduled to complete the baseline survey at the study site within 14 days. A total of 103 participants arrived for the orientation activities and to complete the baseline survey. This $71 \%$ attendance rate between referral and start of a program is significantly higher than the Pennsylvania state average of $50 \%$ attendance from referral to participation activities [68].

\section{Randomization procedures}

After participants provided verbal informed consent, recruitment staff assigned a study ID to participants. Study IDs were 150 random numbers ranging from 1 to 10,000 which were previously assigned to the three study groups, so that each participant was randomly assigned to a particular study group. After randomization, the recruitment staff then conducted a written informed consent procedure for participants, according to the intervention group to which the participants had been assigned.

We used single blinding among three study groups, and program instructors and facilitators were instructed not to discuss any information about other groups with participants.

\section{Data collection procedures}

We used the Audio Computer-Assisted Self-Interview (ACASI) method for baseline and follow-up data collection. The ACASI methodology has been widely used both in randomized controlled trials and in surveys that collect information about sensitive topics and behaviors
$[69,70]$. The ACASI interviews were designed and built through the Questionnaire Development System ${ }^{\mathrm{TM}}$ software, which is developed and sold by NOVA Research Company. Participants from each study group take a $1 \mathrm{~h}$ survey every 3 months, from baseline until 15 months post-recruitment. Incentives of $\$ 25$ in cash and lunch or snacks are provided each time. Resources were made available to all participants after the baseline survey, and the option of following up with a social worker is also made available.

\section{Network RCT program design Full Intervention}

Program activities include helping participants to open savings accounts at a local non-profit federal credit union (with 1:1 matches of up to 20 dollars per month) over the course of 12 months; financial empowerment classes using a curriculum developed especially for this program (3 h classes once per week); and peer support groups called Self Empowerment Groups (SEG) that draw from the Sanctuary ${ }^{\circ}$ trauma-informed approach to social services (two and a half hour sessions once per week) [71]. The SEG curriculum draws key components from the S.E.L.F. tool within Sanctuary, focusing on the four domains: creating personal, emotional, moral and physical safety $(\mathrm{S})$, processing and managing emotions (E), recognizing loss and letting go (L), and developing goals for a sense of future (F). S.E.L.F. establishes a common language that all people who have experienced adversity can use to organize their lives and work towards building stable foundations to support their goals and invest in their potential. To address personal mental health concerns and other health barriers such as housing, 
food, and safety, the staff Social Worker follows up individually and makes a referral to an appropriate agency that could assist them in meeting their needs.

The Financial Empowerment curriculum consists of interactive exercises, worksheets, and journal assignments to foster understanding and practice of banking, building credit and debt management, making the most of one's money, and setting financial goals for oneself and one's family. Content focuses on identifying and harnessing the internal and external resources that participants can leverage to begin taking steps towards financial self-sufficiency. Program group activities are provided for 28 weeks.

Participants are encouraged to make weekly deposits in their account as little or as much as they feel they can for the duration of 12 months. During class sessions, deposits are made in class, with a bank representative available to assist, as well as at branches and ATMs. Understanding that participants relying on TANF income have limited funds to deposit, the goal for the small savings during the program is to launch a practice of asset-building that would carry beyond their participation in TANF. The maximum match of $\$ 240$ minimizes the possibility that participants exceed the TANF asset-limit of $\$ 1000$.

\section{Partial intervention}

This group receives matched savings accounts and financial empowerment education as described above, but does not receive the trauma-informed peer support.

\section{Control group}

The Control group does not receive assistance in opening a matched savings account, and are required by the CAO to participate in other TANF mandated work participation activities according to standard procedure.

Our hypotheses are that over the course of 15 months, those receiving the full intervention would have greater improvements in depression, self-rated health, savings patterns and financial security as compared to those who receive the partial intervention and the control group; and that those receiving the partial intervention may show improvements in financial security as compared to the control group.

\section{Primary outcomes}

All measurements used in The Network RCT survey, including baseline measures reported here, are listed in Table 1. At baseline, we collected information on demographics and socio-economic status, career readiness, family economic hardship, financial behavior, physical and mental health of the participant and his or her youngest child, exposure to adversity and violence, and incarceration. The social and demographic information included participants' age, gender, immigration status, residential zip code, race/ethnicity, marital status, sexual orientation, educational attainment, employment status, and banking participation.

\section{Career readiness}

The career readiness outcomes included two measures: employment hope [72, 73], and general self-efficacy [74]. The employment hope scale was developed and validated by Hong et al., and consists of four components: psychological empowerment, future-oriented self-motivation, utilization of skills and resources, and goal-orientation [72, 73]. The general self-efficacy (GSE) scale was developed by Schwarzer and Jerusalem and found to be reliable and valid [74]. The GSE scale is widely used to assess individual selfefficacy in addressing daily challenges and adapting after stressful events.

\section{Family economic hardship and physical and mental health}

Family economic hardship is captured in three measures: the U.S Household Food Security Survey Module (HFSSM), an energy security survey, and a housing security survey. The HFSSM is a widely used, validated scale developed by U.S. Department of Agriculture to measure food insecurity, meaning the lack of access to enough food for an active and healthy life for the household and/or children [75, 76]. Eighteen questions are asked that include worry about not having enough money for food and reduction in diet quality over the course of 30 days. Household food insecurity consists of two dimensions: low food security, signified by food access problems and reduced quality of diet, and very low food security, signified by reduced food intake and disruption of eating patterns. The household energy security scale was developed and validated to measure access to adequate household heating and cooling [1]. The scale includes four questions to determine level of energy security in the household. Participants answered whether, in the past 3 months, the gas/electric company sent a letter threatening to shut off service for not paying bills, whether energy service was not delivered for not paying bills, whether there were any days in the past 3 months that the home was not heated/cooled because the household could not pay the bills, and whether the cooking stove was used to heat the home because the family could not pay bills. An affirmative response to only the first question (gas/electric company sent a letter threatening to shut-off service) indicates that a household has experienced "moderate energy insecurity". For an affirmative answer to that question and at least one more, the household is considered to be severely energy insecure [1]. The housing security scale was developed and validated to assess access to adequate and stable housing, where housing insecurity is indicated by affirmative 
Table 1 Surveys and Measurements Used in the Building Wealth and Health Network Randomized Controlled Trial Survey

\begin{tabular}{|c|c|c|c|}
\hline Measurements & Scales & References & Frequency \\
\hline \multicolumn{4}{|l|}{ Demographics and socio-economic status } \\
\hline Demographics & $\begin{array}{l}\text { Gender, age, residential zip code, immigration status, } \\
\text { race and ethnicity, marital status, sexual orientation, } \\
\text { educational levels }\end{array}$ & N/A & Baseline only \\
\hline Current employment & Self-report whether currently working & N/A & Baseline/follow-up \\
\hline \multicolumn{4}{|l|}{ Career Readiness } \\
\hline Learning Needs ${ }^{a}$ & $\begin{array}{l}\text { Washington State Learning Needs Screening } \\
\text { Tool 13-item survey }\end{array}$ & $\begin{array}{l}\text { Washington State Division } \\
\text { of Employment and } \\
\text { Social Services, } 1997 \text { [111] }\end{array}$ & Baseline only \\
\hline Employment Hope & $\begin{array}{l}\text { Derived from the Employment Hope Scale } \\
\text { 9-item survey }\end{array}$ & Hong, et al. 2013 [72, 73] & Baseline/follow-up \\
\hline Self-Efficacy & General Self-Efficacy Scale 10-item survey & Schwarzer, et al. 1995 [74] & Baseline/follow-up \\
\hline \multicolumn{4}{|l|}{ Family economic hardship } \\
\hline Food Insecurity & U.S. Household Food Security Survey Module & Bickel, et al., $2000[75,76]$ & Baseline/follow-up \\
\hline Energy Insecurity & Derived from Children's HealthWatch Survey & Cook, et al. 2008 [1] & Baseline/follow-up \\
\hline Housing Insecurity & Derived from Children's HealthWatch Survey & Cutts, et al. 2011 [77] & Baseline/follow-up \\
\hline \multicolumn{4}{|l|}{ Financial Behavior } \\
\hline Financial capability ${ }^{a}$ & $\begin{array}{l}\text { Financial Capability Scale, Developed at University } \\
\text { of Wisconsin Center for Financial Security }\end{array}$ & Collins, et al. 2013 [112] & Baseline/follow-up \\
\hline $\begin{array}{l}\text { Financial Behavior, Knowledge, } \\
\text { and Self-efficacy }\end{array}$ & 4-section, 28-item survey & Danes, et al. 1999 [113] & Baseline/follow-up \\
\hline Entrepreneurship and Savvy ${ }^{a}$ & $\begin{array}{l}\text { 16-item survey question developed by Network } \\
\text { study group }\end{array}$ & N/A & Baseline/follow-up \\
\hline \multicolumn{4}{|l|}{ Physical and mental health related questions } \\
\hline \multicolumn{4}{|l|}{ Adult's Health } \\
\hline Caregiver's General Health & $\begin{array}{l}\text { Self-rated physical health, self-rated physical health } \\
\text { compared to the previous } 3 \text { months }\end{array}$ & N/A & Baseline/follow-up \\
\hline Depression & 10-item short version of CES-D scale & $\begin{array}{l}\text { Radloff, et al., } 1977 \\
{[80,81,82]}\end{array}$ & Baseline/follow-up \\
\hline Substance Use & $\begin{array}{l}\text { Alcohol abuse questions derived from Audit-C, } \\
\text { drug abuse questions derived from DAST-10 } \\
\text { screening test }\end{array}$ & $\begin{array}{l}\text { Babor, et al. } 2002[114], \\
\text { Skinner, et al. [115] }\end{array}$ & Baseline/follow-up \\
\hline \multicolumn{4}{|l|}{ Youngest Child's Health } \\
\hline Caregiver report of child's health history & Derived from NHANES III survey & $\begin{array}{l}\text { National Center for Health } \\
\text { Statistics, } 1990[97]\end{array}$ & Baseline/follow-up \\
\hline Child Development & $\begin{array}{l}\text { Parents' Evaluation of Developmental } \\
\text { Status survey }\end{array}$ & Glascoe, 1998 [84] & Baseline/follow-up \\
\hline \multicolumn{4}{|l|}{ Exposure to Adversity and Violence } \\
\hline Interaction with criminal justice & 8-item survey & $\begin{array}{l}\text { Brooks-Gunn, et al. } 2011 \\
{[116,81]}\end{array}$ & Baseline only \\
\hline $\begin{array}{l}\text { Exposure to } \\
\text { community violence }\end{array}$ & $\begin{array}{l}\text { Survey of Exposure to Community Violence } \\
\text { 14-item survey }\end{array}$ & Richters, et al. 1990 [90] & Baseline only \\
\hline Childhood adversity & Adverse Childhood Experiences 10-item survey & Felitti, et al. 1998 [89] & Baseline only \\
\hline \multicolumn{4}{|l|}{ Social connection } \\
\hline Social Support ${ }^{\mathrm{a}}$ & Social Support Network Scale 12-item survey & Block, et al. 2000 [117] & Baseline/follow-up \\
\hline Social Capital ${ }^{a}$ & $\begin{array}{l}\text { Modified from Internet Social Capital Scales } \\
\text { 20-item survey question }\end{array}$ & Williams, D. 2006 [118] & Baseline/follow-up \\
\hline \multicolumn{4}{|l|}{ Program Evaluation } \\
\hline Network Satisfaction & $\begin{array}{l}\text { 7-item survey developed by } \\
\text { Network study group }\end{array}$ & N/A & Follow-up only \\
\hline
\end{tabular}


response to at least two of the following: overcrowding (more than 2 people per bedroom) or multiple moves (two or more moves in the previous year) [77, 78]. Overall, these three measures of hardship are related to poor self-rated health and depressive symptoms and poor child health and development $[1,77,79]$.

We assessed participants' self-rated mental and physical health, as well as caregiver-rated general health of the participants' youngest child. Adult and child general physical health were identified by self-report health condition in four categories, excellent, good, fair, poor. To assess depressive symptoms among adult participants, we used the short version (10-items) depression screening scale developed by Center for Epidemiologic Studies Depression (CES-D) [80], which has been shown to be reliable and consistent with the original version [81, 82].

Child's developmental risk were measured by the Parents' Evaluation of Developmental Status survey [83], which has a sensitivity of $91-97 \%$ and specificity of $73-86 \%$ and has been validated with disadvantaged populations in the United States [84]. Participants were asked ten questions about their child's developmental issues: global/cognitive, expressive language and articulation, fine-motor, gross motor, behavior, socialemotional, self-help, school, and any other concerns. Prior studies have suggested that two or more childhood developmental concerns can lead to major disability in adult life [85-87]. Glascoe's study indicated that one in ten parents had at least two significant concerns about their child's development [86]. These children for whom two significant concerns are reported at a young age are 20 times more likely to have a disability than children of parents who do not have any concerns [85].

\section{Exposure to adversity and violence and criminal justice system}

Exposure to childhood adversity was measured using the Adverse Childhood Experiences (ACEs) survey, a retrospective 10-item questionnaire that refers to experiences in the first 18 years of life $[88,89]$. The ACEs survey is a widely used, validated survey to assess exposure to physical, emotional, and sexual abuse; physical and emotional neglect; and household dysfunction, including parental separation, domestic violence, and growing up with a household member who was mentally ill, abused substances, or was incarcerated. We assessed participants' exposure to community violence with the Survey of Exposure to Community Violence (SECV), a validated scale developed by Richters et al. $[90,91]$ that includes reports of being a victim of or witness to community violence. We also measured participants' interaction with the criminal justice system $[92,93]$.

\section{Statistical methods}

We used SAS version 9.3 for all data analysis. All statistical tests are two sided. The baseline characteristics of participants in each study arm were assessed using Chisquare for categorical variables and simple t-tests for numerical variables.

\section{Results \\ Demographics}

Of the 103 participants that participated in the baseline survey, 37 were in the full intervention group, 35 in the partial intervention group, and 31 in the control group. Table 2 presents basic characteristics of all participants. The mean age for participants was 25 years old. The youngest child's mean age was 30 months. Majority of participants were women (94.2\%), US-born (98.1\%), Black non-Hispanic (88.4\%), never married (83.5 \%), unemployed (94.2\%), and without a bank account (66\%). Our baseline data indicates that there were no statistically significant differences in social or economic conditions among participants in the three study arms in demographics or other measures.

\section{Career readiness}

Career readiness characteristics are outlined in Table 3. Network participant reports of employment hope are clustered at the top end of the scale with a mean of 128.3 out of 140 maximum score, with over $20 \%$ reaching the maximum score. The employment hope scale is a new scale and there are no nationally representative norms available yet for comparison. The mean for General Self-Efficacy reported at baseline was 31.1 out of a maximum 40 on the scale. This is similar and within range of the mean of 29.5 that has been reported for the general population of the United States [94].

\section{Family economic hardship and health and wellbeing}

At baseline, participants reported economic hardship at higher rates than the general population. As seen in Table 4 , over $30 \%$ of participants reported very low household food security, over five times the national rate of $5.9 \%$ for households with children [76]. About $65 \%$ of participants at baseline reported housing insecurity which includes crowding and/or multiple moves. This is significantly higher than that reported by Cutts et al.'s study in 2011, which indicated that $46 \%$ of families with children under age four, reporting to clinical settings, experienced housing insecurity [77]. A significant percentage $(31.1 \%)$ of participants also reported severe energy insecurity, which is associated with mental distress and depression [95]. This prevalence rate for severe energy insecurity is much higher than the prevalence of severe energy insecurity compared to the $23 \%$ observed in 
Table 2 Baseline Characteristics of the Participants of Building Wealth and Health Network Randomized Controlled Trial

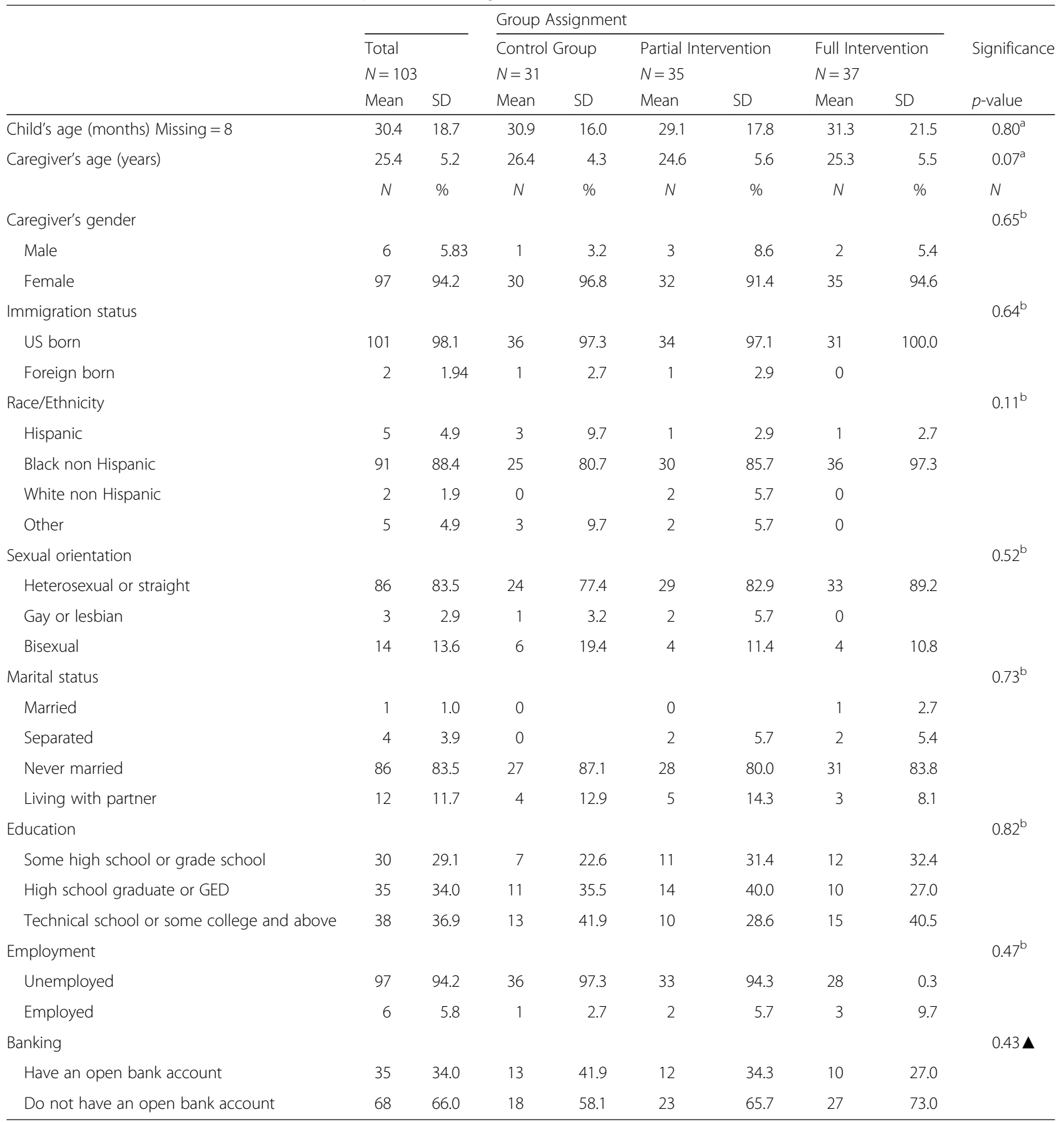

tested by Wilcoxon-Mann-Whitney test

bested by Fisher's Exact test

$\Delta$ tested by Chi-square test

Cook et al.'s 2008 study with caregivers of young children [96].

Slightly over a third (34\%) of adult participants rated their health as fair or poor. This prevalence of fair/poor health is twice that of the general US population [97]. The prevalence of depression (57.3\%) is more than twice that found in the nationally representative
NHANES study [98], and more than eight times the rate reported in the Diagnostic and Statistical Manual of Mental Disorders (DSM) [99]. Results for the health and wellbeing of the participants' youngest child (under age 6), show that over $20 \%$ of the participants considered their youngest child's health as fair or poor, which is significantly higher than the national prevalence rates for 
Table 3 Career Readiness

\begin{tabular}{|c|c|c|}
\hline Employment Hope & Mean & SD \\
\hline When working or looking for a job, I am respectful towards who I am. & 9.7 & 1.0 \\
\hline I am worthy of working in a good job. & 9.7 & 1.0 \\
\hline I am capable of working in a good job. & 9.8 & 0.7 \\
\hline I have the strength to overcome any obstacles when it comes to working. & 9.4 & 1.2 \\
\hline I am going to be working in a career job. & 9.2 & 1.7 \\
\hline I feel energized when I think about future achievement with my job. & 9.3 & 1.5 \\
\hline I am aware of what my skills are to be employed in a good job. & 9.5 & 1.3 \\
\hline I am aware of what my resources are to be employed in a good job. & 9.0 & 1.7 \\
\hline I am able to utilize my skills to move toward career goals. & 9.2 & 1.6 \\
\hline I am able to utilize my resources to move toward career goals. & 9.0 & 1.7 \\
\hline I am on the road toward my career goals. & 8 & 2.7 \\
\hline I am in the process of moving forward reaching my goals. & 8.7 & 2.0 \\
\hline Even if I am not able to achieve my financial goals right away, I will find a way to get there. & 9.4 & 1.3 \\
\hline My current path will take me to where I need to be in my career. & 8.5 & 2.3 \\
\hline General Self-Efficacy & 31.1 & 4.9 \\
\hline I can always manage to solve difficult problems if I try hard enough. & 3.5 & 0.6 \\
\hline If someone is against me, I can find ways to get what I want. & 2.5 & 1.0 \\
\hline It is easy for me to stick to my aims and reach my goals. & 3.2 & 0.8 \\
\hline I am confident that I could deal with unexpected events. & 3.1 & 0.7 \\
\hline Thanks to my resourcefulness, I know how to handle unforeseen situations that I don't expect. & 3.1 & 0.8 \\
\hline I can solve most problems if I put in the necessary effort. & 3.4 & 0.7 \\
\hline I can remain calm when facing difficulties because I can rely on my coping abilities. & 3.0 & 0.9 \\
\hline When I am faced with a problem, I can usually find several solutions. & 3.0 & 0.8 \\
\hline If I am in trouble, I can usually think of a solution. & 3.1 & 0.8 \\
\hline I can usually handle whatever comes my way. & 3.2 & 0.7 \\
\hline
\end{tabular}

children aged 5 years and younger [100]. Additionally, $26 \%$ reported their youngest child had at least one developmental concern, while $10 \%$ reported two or more concerns, for a pooled prevalence rate of $36 \%$, which is higher than pooled prevalence estimate of $31.5 \%$ (95\% CI $27.0-36.0 \%$ ) from a meta-analysis of 37 populationbased studies [101].

\section{Exposure to adversity and violence and interaction with criminal justice}

As seen in Table 5, over $35 \%$ of the participants had four or more ACEs, compared to $6.2 \%$ in a study of 9508 patients in the Kaiser Permanente health care system [102]. The most prevalent experiences included parental separation (71 \%), substance abuse of a household member (43\%), emotional abuse (37\%), and sexual abuse (18\%). These individually reported rates are higher than individual reports recently reported in a population-based sample of Philadelphia residents, where $34.8 \%$ reported substance abuse by household members, $33.2 \%$ reported emotional abuse, and $16.2 \%$ reported sexual abuse [103].

As measured on the Survey of Exposure to Community Violence (SECV), the majority of participants had experienced serious community violence. For example, $60 \%$ of participants reported being slapped, punched, or hit by someone, $30 \%$ reported they had been beaten up or mugged and over $17 \%$ reported being attacked or stabbed with a knife. Additionally, witnessing violence was also prevalent, as $86 \%$ heard sound of gunfire near their homes, $65 \%$ saw a seriously wounded person after an incident of violence, and $27 \%$ had seen someone killed. These findings are comparable to other research on violence exposure among very lowincome parents. For example, one study also using the SECV among adults found that $25 \%$ of the sample had been beaten up or mugged, and a third had seen someone killed [104]. Using a similar measure, the Fragile Families study showed moderate levels of community violence exposure in $29 \%$ of respondents, and high levels in $20 \%$ [105]. 
Table 4 Hardship and Health

\begin{tabular}{|c|c|c|}
\hline Hardship & Number & Percent \\
\hline \multicolumn{3}{|l|}{ Food security status } \\
\hline Food secure & 45 & 43.7 \\
\hline Low food secure & 25 & 24.3 \\
\hline Very low food secure & 33 & 32.0 \\
\hline \multicolumn{3}{|l|}{ Housing security } \\
\hline Housing secure & 36 & 35.0 \\
\hline Housing Insecure & 67 & 65.0 \\
\hline \multicolumn{3}{|l|}{ Energy security } \\
\hline Energy or moderate energy secure & 71 & 68.9 \\
\hline Severe energy insecure & 32 & 31.1 \\
\hline \multicolumn{3}{|l|}{ Physical and Mental Health } \\
\hline Caregiver's Health & Number & Percent \\
\hline \multicolumn{3}{|l|}{ Adult self-rated health } \\
\hline Excellent or good & 68 & 66.0 \\
\hline Fair or poor & 35 & 34.0 \\
\hline \multicolumn{3}{|l|}{ Adult self-report depression (CES-D) } \\
\hline Depression & 59 & 57.3 \\
\hline No depression & 44 & 42.7 \\
\hline \multicolumn{3}{|l|}{ Child's Health } \\
\hline \multicolumn{3}{|l|}{ Adult-rated child's health } \\
\hline Excellent or good & 81 & 78.6 \\
\hline Fair or poor & 22 & 21.3 \\
\hline \multicolumn{3}{|c|}{ Parents' Evaluation of Developmental Status } \\
\hline No significant developmental concern & 71 & 70.3 \\
\hline One significant developmental concern & 16 & 15.8 \\
\hline More than one significant developmental concern & 11 & 10.9 \\
\hline
\end{tabular}

Our baseline findings show that 15 participants (14.6\%) have spent time in an adult correctional institution, with a mean duration of over 2 years and nearly half $(48.5 \%)$ of the fathers of the participants' youngest child has spent time in prison, well above the state average. According to the U.S. Department of Justice, $2.4 \%$ of adult females and $3.3 \%$ of adult males in Pennsylvania were incarcerated in 2013 [106].

\section{Discussion}

The Network RCT is designed to measure the effectiveness of an intervention consisting of financial empowerment education in isolation and in combination with mental health support among TANF recipients with young children. Our baseline data indicates that there were no statistically significant differences in social or economic conditions among the three study arms, which suggested all participants at baseline have been successfully randomized into three study groups.

Variables related to career readiness, employment hope and general self-efficacy do show some promise for the potential of these TANF participants, and may serve as an indication of their potential to succeed in the Building Wealth and Health Network intervention program. Taken together, however, the other baseline data from Network participants paints a bleak picture of severe childhood adversity, adult violence exposure, and multiple poverty-related stressors. Very high levels of food insecurity, housing insecurity, and energy insecurity reflect profound economic hardship among this group of young parents receiving TANF. These too are related to depression, which is reflected in the high rate of depression, where over half of the participants meet the clinical criteria. The high rates of poor health and development of the children in these families reflect the adversity to which they are exposed. Overall, the levels of hardship were significantly higher than that reported in the general population, and in most instances comparable to other very low-income populations.

Despite all of these hardships, every participant in the Network RCT was deemed "work mandatory" and was being held accountable to the $20 \mathrm{~h}$ per week work participation requirement. Given the level of hardship and adversity, and the high-risk nature of their housing and nutrition situations, including exposure to violence, there should be improved screening procedures to deem a person work-ready/work mandatory. Additionally, front-line caseworkers should be empowered to provide a more coordinated, wrap around approach to providing services for at-risk families, and greater support that goes beyond assigning job search activities.

In spite of multiple stressors and adversities, Network RCT participants maintain fairly high levels of selfefficacy and employment hope. These strengths can be drawn upon with appropriate programming to support the aspirations and goals of participants. The Building Wealth and Health Network attempts to incorporate these strengths through building resilience, social support, and opportunities to express self-efficacy.

Due to the nature of our intervention program, we were not able to achieve double blinding in the randomized controlled trial. However, all staff and instructors were trained to minimize bias and to keep all information from other intervention arms confidential during the study. Our study is limited by a small sample size at baseline. However, implementation of missing value imputation might improve power in the later analysis. 
Table 5 Exposure to Adversity and Trauma \& Criminal Justice

\begin{tabular}{lll}
\hline Adult's adverse childhood experiences (ACEs) & Number & Percent \\
\hline 0 ACE & 15 & 14.6 \\
1-3 ACEs & 48 & 46.6 \\
$\geq 4$ ACEs & 40 & 38.8
\end{tabular}

Individual adverse childhood experience

Emotional Abuse

Physical Abuse

Sexual Abuse

Emotional Neglect

Physical Neglect

Parents Separated/Divorced

Mother Abused

Household Substance Abuse

Household Mental IIIness

Household Incarceration

Survey of Exposure to Community Violence

Exposure to Violence

Ever been picked-up, arrested, or taken away by the police

Ever been threatened with serious physical harm 43 by someone

Ever been slapped, punched, or hit by someone

Ever been beaten up or mugged

Ever been attacked or stabbed with a knife

Ever been shot with a gun

\section{Witnessing of violence}

Ever saw someone else getting beaten

Ever heard the sound of gunfire near home

Ever saw a seriously wounded person after an incident of violence

Ever saw someone else being attacked or stabbed with a knife

Ever saw someone else get shot with a gun

Ever saw a dead person somewhere in the community (besides wakes and funerals)

Ever saw someone being killed by another person

Ever heard about someone being killed by another person

Interaction with Criminal Justice System

Did you ever spend time in a youth correctional institution like a training school or reform school?
38

28

18

Table 5 Exposure to Adversity and Trauma \& Criminal Justice (Continued)

\begin{tabular}{lll}
\hline $\begin{array}{l}\text { If "yes" to above: Altogether, how much time did you } \\
\text { spend there? }\end{array}$ & 2.2 & 1.0 \\
& Number & Percent \\
$\begin{array}{l}\text { Did you ever spend time in an adult correctional } \\
\text { institution like a county, state or federal jail or } \\
\text { prison? }\end{array}$ & 15 & 14.6 \\
& Mean & SD \\
$\begin{array}{l}\text { If "yes" to above: Altogether, how much time did you } \\
\text { serve in this adult institution? }\end{array}$ & 0.05 \\
$\begin{array}{l}\text { Did the father of your child spend any time in jail } \\
\text { or prison? }\end{array}$ & 50 & 48.5 \\
$\begin{array}{l}\text { Did the mother of your child spend any time in } \\
\text { jail or prison? }\end{array}$ & 1 & 1.0 \\
\hline
\end{tabular}

There are several strengths in our study. Our rigorous recruitment and research methods demonstrate that a small-scale RCT in a highly complex environment with participants who have major hardships and barriers to employment can be effective. The intervention itself, which combines matched savings, financial empowerment education, and trauma-informed peer support, is a major innovation to TANF. Our baseline data provides insightful information regarding financial hardship, physical and mental wellbeing and exposure to violence that is rarely considered together for TANF recipients.

\section{Conclusion}

These families with young children participating in TANF demonstrate very high levels of adversity and economic hardship, suggesting that safety net programs meant to encourage participation in the workforce should utilize comprehensive and robust approaches to help families access treatment for depression and overcome serious economic hardship related to poor housing and nutrition. Given the high levels of adversity and violence exposure, adding trauma-informed approaches to social services and job search assistance may show demonstrable promise [107, 108]. Two-generation interventions that address the mental health and economic stability of caregivers simultaneously, with the health and development of children, may offer opportunities for successful and stable entry into the workforce $[109,110]$.

Number Percent

$$
15 \quad 14.6
$$

\section{Abbreviations}

ACASI, Audio Computer-Assisted Self-Interview; ACE, Adverse Childhood Experiences; CAO, County Assistant Office; CWDS, Commonwealth Workforce Development System; GSE, General self-efficacy; HFSSM, U.S Household Food Security Survey Module; RCT, Randomized controlled trial; SECV, Survey of Exposure to Community Violence; SEG, Self Empowerment Group; SNAP, Supplemental Nutrition Assistance Program; TANF, Temporary Assistance for Needy Families; WIC, Special Supplemental Nutrition Program for Women, Infants, and Children 


\section{Acknowledgements}

The authors would like to thank Neha Lodaya for her editorial assistance and quality control of the data.

\section{Funding}

This study was supported by funds from Claneil Foundation, Inc., Annie E. Casey Foundation, First Hospital, and TD Bank. Annie E. Casey Foundation provided partial guidance in the study design.

\section{Availability of data and materials}

Data has not currently been made available in a public repository. Funding for this research study was provided through private foundations. At this time, all data is considered proprietary as the study is still ongoing.

\section{Authors' contributions}

JS carried out the baseline data analysis, and wrote the outcomes section of the manuscript. FP coordinated data collection and assisted in writing the manuscript. RK assisted with design of the study and wrote parts of the manuscript. NF implemented the intervention and edited the manuscript, CO assisted with data collection and editing the manuscript, SW assisted with data analysis and assisted with writing. MC designed the study and led the writing of the manuscript. All authors read and approved the final manuscript.

\section{Competing interests}

The authors declare that they have no competing interests.

\section{Ethics approval and consent to participate}

All research participants provided written informed consent prior to any data collection and intervention. Drexel University Institutional Review Board (IORG0000411) approved this research study.

\section{Author details}

${ }^{1}$ Department of Health Management and Policy, Drexel University Dornsife School of Public Health, 3600 Market Street, 7th Floor, Philadelphia, PA

19104, USA. ${ }^{2}$ Department of Epidemiology and Biostatistics, Drexel University Dornsife School of Public Health, 3215 Market Street, 5th Floor, Room 535, Philadelphia, PA 19104, USA. Department of Epidemiology, Johns Hopkins University Bloomberg School of Public Health, 2213 McElderry St, Room M139, Baltimore, MD 21205, USA. ${ }^{4}$ Stockton University, Galloway, NJ 08205-9441, USA.

\section{Received: 27 August 2015 Accepted: 16 June 2016}

Published online: 16 July 2016

\section{References}

1. Cook JT et al. A brief indicator of household energy security: Associations with food security, child health, and child development in US infants and toddlers. Pediatrics. 2008;122(4):e867-75.

2. Loprest P, Maag E. Disabilities among TANF recipients: Evidence from NHIS. Washington, D.C: The Urban Institute; 2009.

3. Danziger SK, Seefeldt KS. Barriers to employment and the 'hard to serve': Implications for services, sanctions, and time limits. Soc Policy Soc. 2003; 2(02):151-160.

4. Kneipp SM, Kairalla JA, Sheely AL. A randomized controlled trial to improve health among women receiving welfare in the U.S.: The relationship between employment outcomes and the economic recession. Soc Sci Med. 2013;80:130-40.

5. Kneipp SM et al. Public Health Nursing Case Management for Women Receiving Temporary Assistance for Needy Families: A Randomized Controlled Trial Using Community-Based Participatory Research. Am J Public Health. 2011;101(9):1759-68.

6. Administration, S.A.a.M.H.S. Trauma-Informed Care in Behavioral Health Services. In: Treatment Improvement Protocol (TIP) Series. Rockville: Substance Abuse and Mental Health Services Administration; 2014.

7. Bloom SL. Creating sanctuary: toward the evolution of sane societies. New York: Routledge; 1997. p. 306

8. Mahlke $\mathrm{Cl}$ et al. Peer support in mental health services. Curr Opin Psychiatry. 2014;27(4):276-81.

9. Mead S, Hilton D, Curtis L. Peer Support: A Theoretical Perspective. Psychiatr Rehabil J. 2001;25(2):134-41.
10. Floyd I, LaDonna P, Schott L. TANF Continues to Weaken as a Safety Net. Center on Budget and Policy Priorities, 2015.

11. Duncan GJ, Brooks-Gunn J. Family poverty, welfare reform, and child development. Child Dev. 2000;71(1):188-96.

12. Black MM et al. WIC participation attenuates child health risks associated with dual stressors of household food insecurity and caregiver depressive symptoms. Arch Pediatr Adolesc Med. 2012;166(5):444-51.

13. Frank DA et al. Nutritional-assistance programs play a critical role in reducing food insecurity. Pediatrics. 2010;125(5):e1267. author reply e1267-8.

14. Dworsky A, Courtney ME. Barriers to employment among TANF applicants and their consequences for self-sufficiency. Fam Soc J Contemp Soc Serv. 2007;88(3):379-89.

15. Trisi D, Pavetti L. TANF Weakening as a Safety Net for Poor Families, in Center on Budget and Policy Priorities, http://www.cbpp.org/cms/index.cfm?fa=view\&id= 3700, Editor. 2012, Center on Budget and Policy Priorities: Washington, D.C.

16. Bloom D, Loprest PJ, Zedlewski SR. TANF recipients with barriers to employment. Washington, DC: The Urban Institute. Temporary Assistance for Needy Families Program—Research Synthesis Brief; 2011. p. 1.

17. Kennedy AC. Urban adolescent mothers exposed to community, family, and partner violence: prevalence, outcomes, and welfare policy implications. Am J Orthopsychiatry. 2006;76(1):44-54.

18. Bowie SL, Dopwell DM. Metastressors as barriers to self-sufficiency among TANF-reliant African American and Latina women. Affilia: Journal of Women and Social Work. 2013;00(0):1-17.

19. Lown EA, Schmidt LA, Wiley J. Interpersonal violence among women seeking welfare: unraveling lives. Am J Public Health. 2006;96(8):1409-15.

20. Raphael J. Keeping battered women safe during welfare reform: new challenges. J Am Med Womens Assoc. 2002;57(1):32-5.

21. Cheng TC. Intimate Partner Violence and Welfare Participation A Longitudinal Causal Analysis. J Interpers Violence. 2013:28(4):808-30.

22. Adams AE et al. Does job stability mediate the relationship between intimate partner violence and mental health among low-income women? Am J Orthopsychiatry. 2013;83(4):600-8.

23. Staggs SL et al. Intimate partner violence, social support, and employment in the post-welfare reform era. J Interpers Violence. 2007;22(3):345-67.

24. Frogner B, Moffit R, Ribar D. Leaving Welfare: Long-Term Evidence from Three Cities. Baltimore: Johns Hopkins University; 2010 in Three City Study, Working Paper 10-01. Baltimore, MD: Johns Hopkins University; 2010.

25. Breiding MJ, et al. Prevalence and characteristics of sexual violence, stalking, and intimate partner violence victimization-National Intimate Partner and Sexual Violence Survey, United States, 2011. Centers for Disease Control and Prevention; 2014

26. Cambron C, Gringeri C, Vogel-Ferguson MB. Physical and mental health correlates of adverse childhood experiences among low-income women. Health \& social work. 2014:39(4):221-9.

27. Danese A et al. Adverse childhood experiences and adult risk factors for age-related disease: depression, inflammation, and clustering of metabolic risk markers. Arch Pediatr Adolesc Med. 2009;163(12):1135-43.

28. Anda RF et al. Adverse childhood experiences and chronic obstructive pulmonary disease in adults. Am J Prev Med. 2008;34(5):396-403.

29. Ross CE, Mirowsky J. Neighborhood disadvantage, disorder, and health. J Health Soc Behav. 2001;42(3):258-76.

30. Chilton $\mathrm{M}$ et al. The relationship between childhood adversity and food insecurity: 'It's like a bird nesting in your head'. Public Health Nutr. 2015;18(14):2643-53.

31. Anda RF et al. Childhood Abuse, Household Dysfunction, and Indicators of Impaired Adult Worker Performance. Perm J. 2004;8(1):30-8.

32. Phillips SD, Dettlaff AJ. More than parents in prison: The broader overlap between the criminal justice and child welfare systems. J Publ Child Welfare. 2009;3(1):3-22.

33. Travis J. Families and Children of Offenders Who Return Home. Fed Probation. 2005;69:31.

34. Head V, Born CE, Ovwigho P. Criminal History as an employment barrier for TANF recipients. Baltimore: University of Maryland Baltimore; 2009.

35. Lu W et al. Correlates of adverse childhood experiences among adults with severe mood disorders. Psychiatr Serv. 2008;59(9):1018-26.

36. Evans GW, Brooks-Gunn J, Klebanov PK, Stressing out the poor: Chronic physiological stress and the income-achievement gap. Community Investments; 2011(Fall): p. 22-27.

37. Liu $Y$ et al. Relationship between adverse childhood experiences and unemployment among adults from five U.S. states. Soc Psychiatry Psychiatr Epidemiol. 2013;48(3):357-69. 
38. Farah MJ et al. Childhood poverty: Specific associations with neurocognitive development. Brain Res. 2006;1110(1):166-74.

39. Noble KG, McCandliss BD, Farah MJ. Socioeconomic gradients predict individual differences in neurocognitive abilities. Dev Sci. 2007;10(4):464-80.

40. Randles JM. Partnering and Parenting in Poverty: A Qualitative Analysis of a Relationship Skills Program for Low-Income, Unmarried Families. J Policy Anal Manage. 2014;33(2):385-412.

41. Larkin H, Felitti VJ, Anda RF. Social work and adverse childhood experiences research: implications for practice and health policy. Soc Work Public Health. 2014;29(1):1-16.

42. Larkin H, MacFarland NS. Restorative integral support (RIS) for older adults experiencing co-occurring disorders. Int J Aging Hum Dev. 2012;74(3):231-41

43. Pavetti L, Derr MK, Hesketh H. Review of sanction policies and research studies, report from Mathematica Policy Research, Inc., to the Office of the Assistant Secretary for Planning and Evaluation, US Department of Health and Human Services (March 2003). 2003.

44. Lindhorst T, Mancoske RJ. The social and economic impact of sanctions and time limits on recipients of temporary assistance to needy families. J Sociol Soc Welf. 2006;33(1):93.

45. Lens V. Work sanctions under welfare reform: Are they helping women achieve self-sufficiency. Duke J Gender L \& Pol'y. 2006;13:255.

46. Pavetti $L$ et al. The use of TANF work-oriented sanctions in Illinois, New Jersey, and South Carolina. Washington, DC: Mathematica Policy Research, Inc; 2004.

47. Cook J et al. Welfare reform and the health of young chidren: A Sentinel survey in 6 US cities. Arch Pediatr Adolesc Med. 2002;156(7):678.

48. Kalil A, Seefeldt KS, Wang HC. Sanctions and material hardship under TANF. Soc Serv Rev. 2002;76(4):642-62.

49. Oggins J, Fleming A. Welfare reform sanctions and financial strain in a foodpantry sample. J Soc \& Soc Welfare. 2001;28:101

50. Reichman NE, Teitler JO, Curtis MA. TANF Sanctioning and Hardship. Soc Serv Rev. 2005;79(2):215-36. 403-404.

51. Larson AM, Singh S, Lewis C. Sanctions and Education Outcomes for Children in TANF Families. Child Youth Services. 2011;32(3):180-99.

52. Stegman MA, Faris R. Welfare, work and banking: The use of consume credit by current and former TANF recipients in Charlotte, North Carolina. J Urban Aff. 2005;27(4):379-402.

53. Zhan M, Anderson SG, Scott J. Financial management knowledge of the lowincome population: Characteristics and needs. J Soc Serv Res. 2006;33(1):93-106.

54. Anderson S, Zhan M, Scott J. Improving the knowledge and attitudes of low-income families about banking and predatory financial practices. Fam Soc J Contemp Soc Serv. 2007;88(3):443-52.

55. Sullivan JX. Welfare Reform, Saving, and Vehicle Ownership Do Asset Limits and Vehicle Exemptions Matter? J Hum Resour. 2006;41(1):72-105.

56. FDIC Unbanked/Underbanked Survey Study Group. 2011 FDIC National Survey of Unbanked and Underbanked Households. Federal Deposit Ensurance Corporation, editor. Washington, D.C.: Federal Deposit Ensurance Corporation; 2012.

57. Sherraden MW. Assets and the poor: a new American welfare policy. Armonk: M.E. Sharpe; 1991. p. 324.

58. Shapiro TM, Wolff EN. Assets for the poor: the benefits of spreading asset ownership, The Ford Foundation series on asset building. New York: Russell Sage; 2001. p. 389.

59. Sherraden MW. Inclusion in the American dream: assets, poverty, and public policy. New York: Oxford University Press; 2005. 409.

60. Shanks TR, Robinson C. Over-stressed kids: Examining the impact of economic security on children and families. Annie E. Casey Foundation, editor. Baltimore, MD: 2011.

61. Brooks, J, Wiedrich K. Assets \& Opportunity Scorecard: A Portrait of financial insecurity and Policies to Rebuild Prosperity in America, in CFED, http://scorecard. cfed.org, Editor. 2012: Washington, D.C.

62. Hendey L, McKernan S-M, Woo B. Weathering the Recession: The Financial Crisis and Family Wealth Changes in Low-Income Neighborhoods. The Annie E. Casey Foundation and the Urban Institute, editor. Baltimore, MD and Washington, DC; 2012

63. Collins JM. Effects of mandatory financial education on low-income clients Focus. 2010;27(1):13-8.

64. Elliott W, Beverly SG. The role of savings and wealth in reducing 'wilt' between expectations and college attendance. J Child Poverty. 2011;17(2):165-85.

65. Edin K. More than Money: The Role of Assets in the Survival Strategies and Material Well-being of the Poor, in Assets for the poor: the benefits of spreading asset ownership. New York: Russell Sage Foundation; 2001. p. 206-231.
66. Choi L, et al. For what it's worth: Strengthening the financial future of families, communities and the nation. Washington, DC: Federal Reserve Bank of San Francisco \& Corporation for Enterprise Development; 2015

67. US Department Of Health And Human Services. Strengthening TANF Outcomes By Developing Two-Generation Approaches, Administration For Children And Families Office Of Family Assistance, editor. Washington DC: Information Memoranda TANF-ACF-IM-2016-03; 2016.

68. Pennsylvania State Administrators. Participation Rates for TANF Referrals. 2014.

69. Pluhar E et al. Implementation of audio computer-assisted interviewing software in HIV/AIDS research. J Assoc Nurses AIDS Care. 2007;18(4):51-63.

70. Fernandez Ml et al. Development of an easy to use tool to assess HIV treatment readiness in adolescent clinical care settings. AIDS Care. 2011; 23(11):1492-9.

71. Bloom SL, Sreedhar SY. The sanctuary model of trauma-informed organizational change. Reclaiming Children Youth. 2008;17(3):48-53.

72. Hong P, Polanin J, Pigott T. Validation of the Employment Hope Scale: measuring psychological self-sufficiency among low-income jobseekers. Res Soc Work Pract. 2012;22(3):323-32.

73. Hong PYP. The employment hope scale: Measuring an empowerment pathway to employment success. Int J Psychol Res. 2013;8(3).

74. Schwarzer R, Jerusalem M. Generalized Self-Efficacy scale, in Measures in health psychology: A user's portfolio. Causal and control beliefs. Weinman J, Wright S, Johnston M. Editors. Windsor, England: NFER-NELSON; 1995 p. 35-37.

75. Bickel G. et al. Guide to measuring household food security. US Department of Agriculture, Food and Nutrition Service, Office of Analysis, Nutrition, and Evaluation. Washington, DC.

76. Bickel $\mathrm{G}$ et al. Measuring Food Security in the United States: Guide to Measuring Household Food Security. Alexandria: US Department of Agriculture, Food and Nutrition Service, Office of Analysis and Evaluation; 2000.

77. Cutts DB et al. US Housing insecurity and the health of very young children. Am J Public Health. 2011;101(8):1508-14.

78. Blake KS, Kellerson RL, Simic A. Measuring overcrowding in housing. Washington, DC: Department of Housing and Urban Development, Office of Policy Development and Research; 2007.

79. Casey $P$ et al. Maternal depression, changing public assistance, food security, and child health status. Pediatrics. 2004;113(2):298-304.

80. Radloff LS. The CES-D scale: A self-report depression scale for research in the general population. Appl Psychol Meas. 1977;1:385-401.

81. Hann D, Winter $K$, Jacobsen P. Measurement of depressive symptoms in cancer patients: evaluation of the Center for Epidemiological Studies Depression Scale (CES-D). J Psychosom Res. 1999;46(5):437-43.

82. Zhang $W$ et al. Validating a Shortened Depression Scale (10 Item CES-D) among HIV-Positive People in British Columbia, Canada. Plos One. 2012;7(7):e40793.

83. Glascoe FP. Scoring, Administration and Interpretation Guidelines, in Collaborating with parents: Using Parents' Evaluation of Developmental Status to detect and address developmental and behavioral problems. Nolensville, TN: Ellsworth \& Vandermeer Press; 1998. p. 9-30.

84. Brothers KB, Glascoe FP, Robertshaw NS. PEDS: Developmental MilestonesAn Accurate Brief Tool for Surveillance and Screening. Clin Pediatr (Phila). 2008:47(3):271-9.

85. Glascoe FP. Collaborating with parents: Using Parents' Evaluation of Developmental Status to detect and address developmental and behavioral problems. Nolensville, TN: Ellsworth \& Vandermeer Press; 1998.

86. Glascoe FP. Parents' evaluation of developmental status: how well do parents' concerns identify children with behavioral and emotional problems? Clin Pediatr (Phila). 2003;42(2):133-8.

87. Glascoe FPMK. Detecting children with developmental-behavioral problems: the value of collaborating with parents. Psychol Test Assess Model. 2011;53(2):258-79.

88. Dong MX et al. The interrelatedness of multiple forms of childhood abuse, neglect, and household dysfunction. Child Abuse Negl. 2004;28(7):771-84.

89. Edwards VJ et al. Relationship between multiple forms of childhood maltreatment and adult mental health in community respondents: Results from the adverse childhood experiences study. Am J Psychiatry. 2003;160(8):1453-1460.

90. Richters JE, Saltzman W. Survey of Exposure to Community Violence: Parent report version. 1990. J.E. Richters.

91. Scarpa A et al. Community Violence Exposure in University Students A Replication and Extension. J Interpers Violence. 2002;17(3):253-72.

92. Osborne C, Knab J. Work, welfare, and young children's health and behavior in the Fragile Families and Child Wellbeing Study. Child Youth Serv Rev. 2007;29(6):762-81. 
93. Wildeman C. Paternal Incarceration and Children's Physically Aggressive Behaviors Evidence from the Fragile Families and Child Wellbeing Study. Social Forces. 2010;89(1):285-309.

94. Schwarzer R. Everything you wanted to know about the General SelfEfficacy Scale but were afraid to ask: documentation of the General SelfEfficacy Scale. 2014.

95. Miller $\mathrm{L}$, World Federation for Mental Health. Mental health in rapid social change. Jerusalem: Jerusalem Academic Press; 1972. p. 415

96. Barkley RA. Barkley deficits in executive functioning scale (BDEFS). Guilford Press; 2011

97. Center for Disease Control and Prevention. Percentage of adults reporting fair or poor self-rated health by demographic characteristics, chronic conditions, and risk factors Adults $>=18$ Years, BRFSS 2009. Available from: http://www.cdc.gov/hrqol/hrqoldata/index.html.

98. Löwe B et al. Measuring depression outcome with a brief self-report instrument: sensitivity to change of the Patient Health Questionnaire (PHQ9). J Affect Disord. 2004;81(1):61-6.

99. American Psychiatric Association. Diagnostic and Statistical Manual of Mental Disorders (DSM-5). American Psychiatric Pub; 2013.

100. Alaimo K, Olson CM, Frongillo Jr EA. Food insufficiency and American school-aged children's cognitive, academic, and psychosocial development. Pediatrics. 2001;108(1):44-53.

101. Woolfenden S et al. A systematic review of the prevalence of parental concerns measured by the Parents' Evaluation of Developmental Status (PEDS) indicating developmental risk. BMC Pediatr. 2014;14(1):231.

102. Felitti $\vee$ et al. Relationship of childhood abuse and household dysfunction to many of the leading causes of death in adults: The Adverse Childhood Experiences (ACE) study. Am J Prev Med. 1998;14(4):245-58.

103. Cronholm P. Adverse Childhood Experiences Expanding the Concept of Adversity. Am J Prev Med. 2015;49(3):354-61.

104. Kliewer W, Zaharakis N. Community violence exposure, coping, and problematic alcohol and drug use among urban, female caregivers: A prospective study. Personal Individ Differ. 2013;55(4):361-6.

105. Zhang S, Anderson SG. Low-income single mothers' community violence exposure and aggressive parenting practices. Child Youth Serv Rev. 2010; 32(6):889-95.

106. Carson E. Prisoners in 2013, in Bureau of Justice Statistics, Office of Justice Programs, Editor. 2014, NCJ 247282, U.S. Department of Justice: Washington, DC.

107. Substance Abuse and Mental Health Services Administration, SAMHSA's Concept of Trauma and Guidance for a Trauma-Informed Approach. 2014, HHS Publication No. (SMA) 14-4884; Substance Abuse and Mental Health Services Administration: Rockville, MD.

108. Murphy A et al. Group attachment-based intervention: Trauma-informed care for families with Adverse Childhood Experiences. Family Community Health. 2015;38(3):268-79.

109. Mosle A, Patel N. Two Generations, One Future: Moving Parents and Children Beyond Poverty Together. The Aspen Institute; 2012

110. Shonkoff JP, Fisher PA. Rethinking evidence-based practice and twogeneration programs to create the future of early childhood policy. Dev Psychopathol. 2013;25(4 pt2):1635-53

111. Payne N. The Washington State Learning Disabilities Screening. Washington State Department of Social and Health Services. 1997.

112. Collins JM. Finding a Yardstick: Field Testing Outcome Measures for Community-based Financial Coaching and Capability Programs. Research Outcomes Brief, Center for Financial Security, Editor. University of WisconsinMadison: Madison, Wisconsin. 2013.

113. Danes SM, C Huddleston-Casas, L Boyce. Financial planning curriculum for teens: impact evaluation. Financial Counseling and Planning, 1999;10(1):25-37.

114. Babor TF, et al. The Alcohol Use Disorders Identification Test. Guidelines for Use in Primary Care. 2nd ed. New York (USA): World Health OrganizationWHO; 2002.

115. Skinner HA. The Drug-Abuse Screening-Test. Addictive Behaviors, 1982;7(4):363-371.

116. Brooks-Gunn J, et al. Fragile Families and Child Wellbeing Study [Public Use Data]. Ann Arbor, MI: Inter-university Consortium for Political and Social Research (ICPSR). 2011

117. Block CR, et al. The Chicago women's health risk study: Risk of serious injury or death in intimate violence, A collaborative research project. Illinois Criminal Justice Information Authority, 2000.

118. Williams D. On and off the'Net: Scales for social capital in an online era. Journal of Computer-Mediated Communication, 2006;11(2):593-628.

\section{Submit your next manuscript to BioMed Central and we will help you at every step:}

- We accept pre-submission inquiries

- Our selector tool helps you to find the most relevant journal

- We provide round the clock customer support

- Convenient online submission

- Thorough peer review

- Inclusion in PubMed and all major indexing services

- Maximum visibility for your research

Submit your manuscript at www.biomedcentral.com/submit
Biomed Central 